Poster sessions

Abstract P129 Table 1. Results are mean values (SD), except for gender. For 1-way ANOVA, $p<0.05$ is significant. Superscript letters indicate significant difference(s) between groups.

\begin{tabular}{|c|c|c|c|c|c|}
\hline Variable & $\begin{array}{l}\text { Group A } \\
(\mathrm{N}=25)\end{array}$ & $\begin{array}{l}\text { Group B } \\
(\mathrm{N}=130)\end{array}$ & $\begin{array}{l}\text { Group C } \\
(\mathrm{N}=14)\end{array}$ & $\begin{array}{l}\text { Group D } \\
(\mathrm{N}=226)\end{array}$ & $\begin{array}{l}\text { 1-way ANOVA } \\
\text { (p-value) }\end{array}$ \\
\hline Gender Male (\%) & $19(76)$ & $79(61)$ & $9(64)$ & $129(56)$ & 0.300 \\
\hline Age (Mean years) & $70(7)$ & $68(8)$ & $67(7)$ & $67(8)$ & 0.070 \\
\hline BMI $\left(\mathrm{kg} / \mathrm{m}^{2}\right)$ & $26.9(4.1)$ & $28.1(5.1)^{C}$ & $24.2(3.6)^{\mathrm{B}}$ & $26.8(5.7)$ & 0.030 \\
\hline $\mathrm{FEV}_{1} \%$ predicted & $67.6(8.7)^{C, D}$ & $64.0(8.5)^{C, D}$ & $47.3(12.8)^{A, B}$ & $47.3(15.5)^{A, B}$ & $<0.001$ \\
\hline $\mathrm{FEV}_{1}(\mathrm{~L})$ & $1.7(0.4)^{C, D}$ & $1.6(0.5)^{C, D}$ & $1.3(0.3)^{\mathrm{A}, \mathrm{B}}$ & $1.3(1.9)^{\mathrm{A}, \mathrm{B}}$ & $<0.001$ \\
\hline Smoking pack years & $45(24)$ & $47(25)$ & $34(16)$ & $48(27)$ & 0.200 \\
\hline Fibrinogen ( $g / L)$ & $3.4(0.9)$ & $3.33(0.9)^{\mathrm{D}}$ & $3.51(0.9)$ & $3.66(0.9)^{\mathrm{B}}$ & 0.008 \\
\hline QMVC (Kg) & $37.1(10.8)^{D}$ & $32.4(11.4)^{\mathrm{D}}$ & $36.4(10.4)^{\mathrm{D}}$ & $29.2(10.3)^{A, B, C}$ & $<0.001$ \\
\hline QMVC/BMI & $1.4(0.4)^{B, D}$ & $1.2(0.4)^{A, C}$ & $1.5(0.4)^{B, D}$ & $1.1(0.4)^{A, C}$ & $<0.001$ \\
\hline 6MWD (m) & $441(106)^{D}$ & $379(110)^{\mathrm{D}}$ & $440(75)^{D}$ & $313(121)^{A, B, C}$ & $<0.001$ \\
\hline APWV (m/s) & $10.6(2.7)$ & $10.2(2.7)$ & $9.4(2.2)$ & $10.3(2.8)$ & 0.600 \\
\hline
\end{tabular}

Disease) consortium (work package 1) cohort categorised by GOLD Group (ABCD).

Methods ERICA is a multicentre UK study investigating the role of inflammation and the prevalence and significance of cardiovascular and skeletal muscle manifestations in COPD. This interim analysis was conducted on 395 (49\%) of 800 planned participants. Measurements include aortic pulse wave velocity (APWV) to measure arterial stiffness, quadriceps maximal voluntary contraction force (QMVC), plasma fibrinogen and 6-minute walk distance (6MWD). We defined arterial stiffness as APWV $>10 \mathrm{~m} / \mathrm{s}$, and skeletal muscle weakness as QMVC/BMI (Body Mass Index) ratio $>1.2$.

Results 395 subjects were classified according to GOLD groups using the mMRC (modified Medical Research Council) dyspnoea scale to evaluate symptoms, (Table 1 ). The majority of subjects were in groups D (57\%) and B (33\%), with low numbers observed in groups A (6\%) and C (4\%). Higher levels of airflow limitation were observed in groups $C \& D(p=0.012)$. Fibrinogen was higher in groups $C \& D(p=0.001)$, consistent with COPD severity.

Group D had reduced 6MWD and quadriceps strength consistent with the hypothesis that they have more severe extra-pulmonary manifestations of COPD and increased risk of mortality. Of note, Group B ('high symptom, low risk') also had reduced quadriceps strength and 6MWD, although for 6MWD this reduction ( $\mathrm{p}=0.06$ compared to group $\mathrm{A}$ ) was not as profound as Group D ( $\mathrm{p}<0.001)$. No difference between groups was observed for APWV.

Conclusion The GOLD group classification captures risk related to skeletal muscle weakness but not arterial stiffness and indicates groups B \& D may benefit from intensive exercise therapy.

\section{P130 IMPACT OF LEFT VENTRICULAR HYPERTROPHY ON MORTALITY IN COPD}

PM Short, WJ Anderson, DH Elder, AD Struthers, BJ Lipworth; Medical Research Institute, University of Dundee, Dundee, UK

\subsection{6/thoraxjnl-2013-204457.280}

Introduction and Objectives Left ventricular hypertrophy (LVH) is a significant risk factor of cardiovascular disease and is associated with increased mortality. Previous studies have shown an increased prevalence of $\mathrm{LVH}$ in normoxaemic COPD patients. The impact of LVH on mortality in COPD is yet to be established.

We evaluated the impact of LVH on mortality in COPD patients by measurement of left ventricular dimensions by echocardiography.
Methods We performed a retrospective cohort study utilising a NHS database of COPD patients (TARDIS) in Tayside, Scotland between 2001 and 2010 that was linked with NHS Tayside databases regarding echocardiograms, pharmacy prescription and the General Register Office for Scotland death registry. Left ventricular internal diastolic diameter (LVIDd) and left ventricular mass index (LVMI) were measured. Increased LVIDd was defined as $>5.3 \mathrm{~cm}$ (female) and $>5.9 \mathrm{~cm}$ (male). LVMI was obtained by correcting the left ventricular mass to body surface area. LVH was defined as an LVMI of $>95 \mathrm{~g} / \mathrm{m}^{2}$ (female) and $>115 \mathrm{~g} / \mathrm{m}^{2}$ (male). Patients with aortic valve disease were excluded from the analysis. The impact of increased LVIDd and LVMI on mortality were evaluated by Kaplan Meir testing and Cox Regression analyses after inclusion of covariates (age, $\mathrm{FEV}_{1} \%, \mathrm{SaO}_{2} \%$, history of diabetes and cardiovascular disease, medication (aspirin, ACEinhibitor, statin, beta blocker).

Results 617 patients were included for analysis. Mean (SD) age at diagnosis, 70 (9); mean $\mathrm{FEV}_{1} \%$ (SD), 60.6 (19.3); mean resting $\mathrm{SaO}_{2} \%$ (SD), 92.7 (10). Mean follow up 4.5 years. Increased LVIDd was not associated with increased mortality, $\mathrm{X}^{2}=0.767$, $\mathrm{p}=0.381$. Increased LVMI was associated with a significant increased risk of mortality, $\mathrm{X}^{2}=5.447, \mathrm{p}=0.02$. with an adjusted HR (95\%CI) of $1.542(1.068-2.228), \mathrm{p}=0.021$. (see graph below).

Conclusion The presence of left ventricular hypertrophy, demonstrated by elevated left ventricular mass index is associated with a significantly increased risk of mortality in COPD patients. Therapeutic interventions are required to address this important modifiable risk factor in COPD patients.

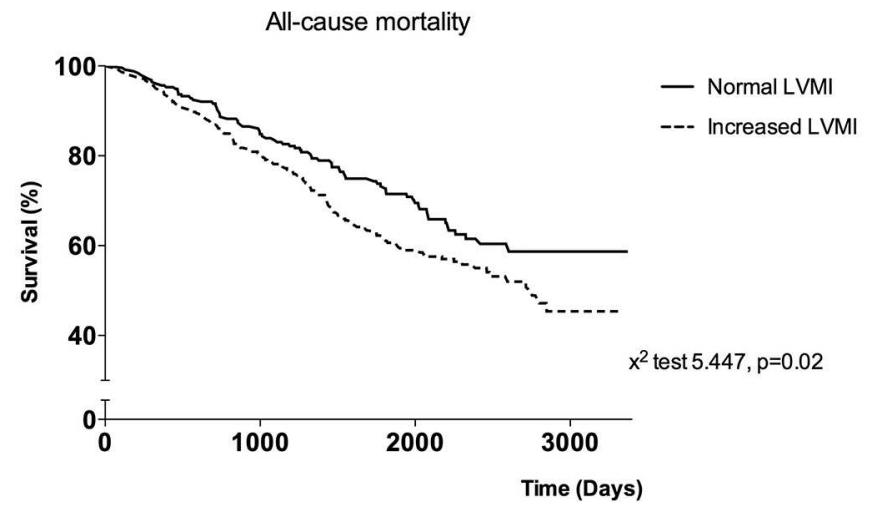

Abstract P130 Figure1 Kaplan _meier estimate of probability of survival dependent on LVMI. Increased LVMI; (male $>115 \mathrm{~g} / \mathrm{m}^{2}$ or female $>95 \mathrm{~g} / \mathrm{m}^{2}$ ) 